\title{
Defects related luminescence in yttrium-aluminum garnet crystals
}

\author{
N.Shiran, A.Gektin, K.Hubenko, V.Nesterkina, \\ P.Arhipov, S.Tkachenko, O.Sidletskiy \\ Institute for Scintillation Materials, STC "Institute for Single Crystals"
National Academy of Sciences of Ukraine, 60 Lenina Ave., 61001
Kharkov, Ukraine
}

Received April 15, 2016

\begin{abstract}
Correlation between growth conditions, point defects appearance, their absorption and spectral-kinetic luminescence characteristics in yttrium-aluminum garnet-based crystals is analyzed. The physical processes are strongly related to the intrinsic lattice defects and composition deviation from the stoichiometry. It is shown that presence of antisite and vacancy-type defects or foreign atoms incorporation results in additional channels of excitation energy dissipation in pure and doped yttrium-aluminum garnet crystals.

Keywords: yttrium-aluminum garnet, stoichiometry, defect emission, antisites, cation and oxygen vacancies, color centers.
\end{abstract}

Рассмотрены кристаллохимические особенности свойств соединений со структурой граната, определяющие проявление отклонений от стехиометрического состава. Представлены результаты исследования абсорбционных и люминесцентных параметров кристаллов алюмоиттриевых гранатов YAG. Установлено, что наблюдаемые спектральные характеристики зависят от наличия собственных дефектов и следов примесей. Показано, что нарушение структуры приводит к появлению дополнительных каналов потерь при переносе энергии.

Люмінесценція дефектів у кристалах алюмоітрісвих гранатів. Н.Ширан, О.Гектін, К.Губенко, В.Нєстєркіна, П.Архіпов, С.Ткаченко, О.Сідлецький.

Розглядаються кристалохімічні особливості властивостей сполук із структурою гранату, які визначають відхилення від стехіометричного складу. Приведено результати досліджень абсорбційних і люмінесцентних параметрів кристалів алюмоітрієвих гранатів YAG. Встановлено, що спектральні характеристики залежать від наявності власних дефектів і домішок. Показано, що порушення структури призводить до появи додаткових каналів втрат при переносі енергії.

\section{Introduction}

Yttrium-aluminum garnet crystals (YAG) are very popular not only in scintillation, but in optical and laser physics and applications. All garnet crystals grown from melt have non-stoichiometric defects due to different volatile raw material components leading to the incorporation of yttrium into $\mathrm{Al}^{3+}$ octahedral sites. Stoichiometry deviation in YAG crystals are studied by XRD and lumines- cence methods [1-3]. Estimation of the defects quantity and experimental data show that the defects concentration could be high and depends on the growh conditions. The nature of these defects appearance points that they could not be fully removed by post growth heat treatment.

Usually three main non-stoichiometric defects are dominated in garnets: antisite defects, cation and oxygen vacancies. General mechanisms of the defect formation looks as the follows [4-6]: 
- Disorder in the garnets is associated with formation of the antisite cation defects. Formation of the Schottky and Frenkel disorder involves much higher energies.

- Incorporation of excess $\mathrm{Y}_{2} \mathrm{O}_{3}$ or lanthanide oxide in the garnet phase is energetically preferable in comparison with incorporation of excess $\mathrm{B}_{2} \mathrm{O}_{3}(\mathrm{~B}=\mathrm{Al}$, Fe, Ga). This result explains the strong nonstoichiometry experimentally found in the garnets. The trend of the solution energy is in qualitative agreement with the available solubility data of $\mathrm{Y}_{2} \mathrm{O}_{3}$ in the gallium garnets.

- Excess of either $\mathrm{Y}_{2} \mathrm{O}_{3}$ or $\mathrm{Al}_{2} \mathrm{O}_{3}$ appears to be the main source of oxygen vacancies in $\mathrm{Al}$ and $\mathrm{Ga}$ garnets.

- Energetically favorable mechanism for oxygen nonstoichiometry compensation in some garnets is provided by the easy reduction of $\mathrm{A}^{3+}$ to $\mathrm{A}^{2+}$ (A-admixture).

Diversity of defects configurations claim for more complex mechanisms of defect formation in garnets [1-6]. For quantitative estimation of the defects concentration the antisites were considered as dominant [2]. In particular, it was assumed that antisite defects in YAG are the part of $Y$ ions substituted by $A l$ ions into the octahedral-coordinated sites. The $\mathrm{Y}_{\mathrm{Al}}{ }^{3+}$ and other antisite defects (AD), as the analogues of isoelectronic impurities, create the centers of luminescence in UV region and related trap centers. In the garnet single crystals, which are grown from melt at high temperatures $\left(T_{m} \geq 1900^{\circ} \mathrm{C}\right)$, concentration of the antisites reaches the value of $0.2-0.5$ at $\%$.

In general it has to be noted that defect type and concentration depend on the crystal growth details and significantly differ for powder, bulk sample, ceramics and thin films [2,7-10]. Optical and luminescence activity of the defects are different depending on the structure and ability to capture carriers with color centers creation. In the last case the crystal is colored and potentially can emit the light after the thermal and/or optical stimulation.

YAG based crystals and related crystals can be obtained by different technologies like horizontal freeze technique, micro-pulling down, liquid phase epitaxy, Edge-defined Film-Fed Growth (EFG), Stepanov technique, etc, [12-15], but the dominant tecbhique is the Czochralski (CZ) process. As it was noted in [14] the amount of publications dealing with the $\mathrm{CZ}$ growth exceeds the total number of papers related to all other technique. This connects with the use of different growth conditions: raw material type, temperature regime, crucible material (Ir, Mo or W), atmosphere, etc. It was revealed that it is almost impossible, even under the same conditions, to growth crystals with the same properties. This is called by the difference in post growth defects type and concentration [14, 15]. Spectroscopic characterization is the most sensitive method for defects verification. In the frame of this article we attempt to make the broad analysis of correlation between crystal growth technique, point defects appearance and optical properties of pure YAG crystals obtained under the different growth conditions. In particular, we study undoped crystals, because activator ion introduction into the lattice influences the luminescence features and masks the manifestation of the initial point defects.

The aim of the current research is an experimental study of the defects impact on YAG absorption, emission and scintillator performance, which demonstrates the variable emission in the single crystals grown by the Czochralski technique.

\section{Experimental}

Series of YAG single crystal with $30 \mathrm{~mm}$ diameter and $150 \mathrm{~mm}$ length were obtained from stoichiometric melt by the Czochralski technique from Ir and Mo crucibles under controlled atmosphere as was previously described [16]. The crystals were subjected to the post-grown heat treatment under air, carbon monoxide and oxygen atmospheres. Their absorption, photo- and radioluminescence spectra, as well as thermostimulated luminescence were studied. The absorption spectra in UV-VIS range were measured by means of a SPECORD 40 spectrophotometer. Spectral characteristics of the photoemission were obtained using a FLS 920 combined steady state and fluorescence lifetime spectrometer. A Xe900 Xenon lamp was used as a source of UV excitation. Kinetic measurements were made using a nF900 nanosecond flash lamp. The X-ray luminescence was excited by an X-ray tube (Cu-anode, $30 \mathrm{~mA}$, $35 \mathrm{kV})$. Thermostimulated luminescence curves was registered in the range of $20-$ $450^{\circ} \mathrm{C}$ under heating the rate of $0.2^{\circ} \mathrm{C} / \mathrm{sec}$.

\section{Results and discussion}

As mentioned above, the features of YAG single crystal growth process (temperature gradient, growth atmosphere, doping con- 

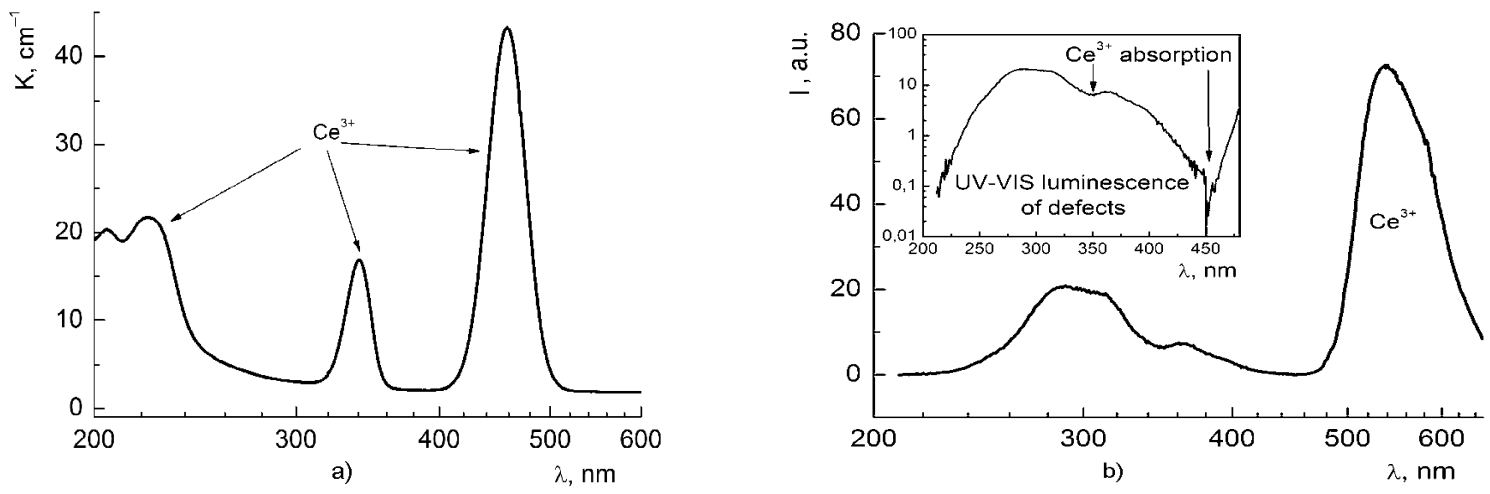

Fig. 1. Absorption (a) and X-ray luminescence specra (b) of YAG:Ce crystal. Insert: UV part of luminescence.

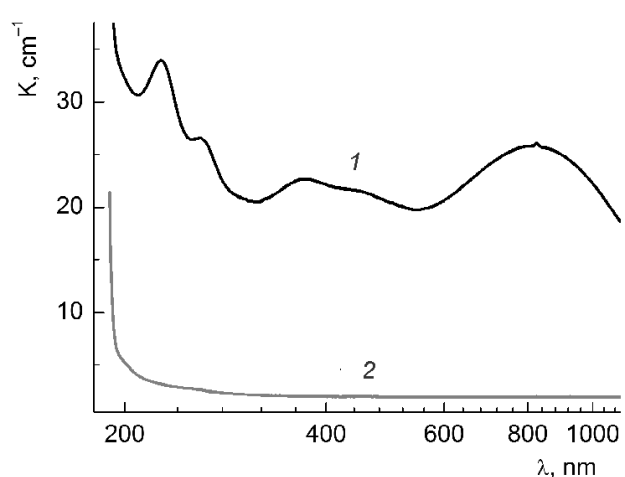

Fig. 2. Absorption spectra of YAG samples from top and bottom of ingots grown in Ir crucible under atmosphere of $\mathrm{Ar}+1.5 \% \quad \mathrm{O}_{2}$ (2) and in Mo crucible in reduced atmosphere (1).

centration, accidental impurities) affect the crystal performance.

Absorption and X-ray luminescence spectra of YAG:Ce scintillation crystal grown by the Cz-technique are presented in Fig. 1. Additional absorption and UV luminescence bands suggest the presence of some defects in $\mathrm{Ce}$ doped YAG crystals. The similar bands reveal in crystals without cerium. Absorption spectra of the nominally pure YAG crystal grown from the same raw material under different conditions are given as an example of the atmosphere influence (Fig. 2). The ingot obtained in Ir crucible under the atmosphere of $\mathrm{Ar}+1.5 \% \quad \mathrm{O}_{2}$ is transparent. It is remarkable that absorption of crystal grown in Mo crucible under reduced conditions looks black and opaque. Coloration density depends on the melting process duration. So the melt is depleted by oxygen and aluminum and the growing crystal acquires an excess of anionic and cationic vacancies, their aggregates and color centers. Destruction of these nonequilibrium growth defects occurs at the beginning of the

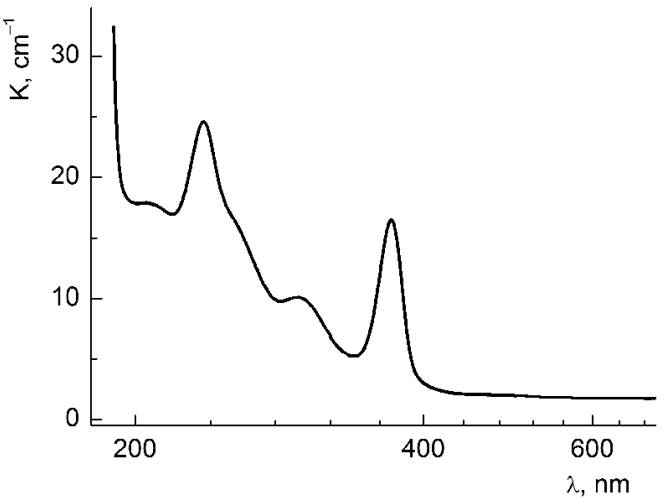

Fig. 3. Absorption spectra of YAG crystal grown under reduced atmosphere.

ionic conductivity $\left(T>900^{\circ} \mathrm{C}\right)$. The special post growth annealing of the crystals (in $\mathrm{O}_{2}$ and $\mathrm{Al}$ atmosphere) suppresses the undesirable absorption and provides the high transparency [24]. The absorption spectrum of YAG crystals grown under the the reducing (CO) atmosphere consists of two intense absorption bands at 235 and $370 \mathrm{~nm}$ (Fig. 3). Excitation in these bands causes the appearance of the narrow luminescence band at $396 \mathrm{~nm}$ (half width $0.26 \mathrm{eV}$ ) (Fig. 4). This emission has a fast decay constant ( $2 \mathrm{~ns})$. Thermostimulated luminescence (TSL) was detected after X-ray irradiation (Fig. 4, insert). Previously the similar characteristics were reported for carbon enriched YAG powder and single crystals wherein the intensity of photoluminescence and TSL are strongly dependent on carbon concentration [19-21]. The carbon doped yttrium-aluminum garnet (YAG:C) showed a high sensitivity to X-ray and UV irradiation and was proposed as a candidate for application in dosimeters. Our results points out that the carbon ions play a decisive role in the TL efficiency. It is noteworthy that the absorption coefficient for the UV peaks in the studied 


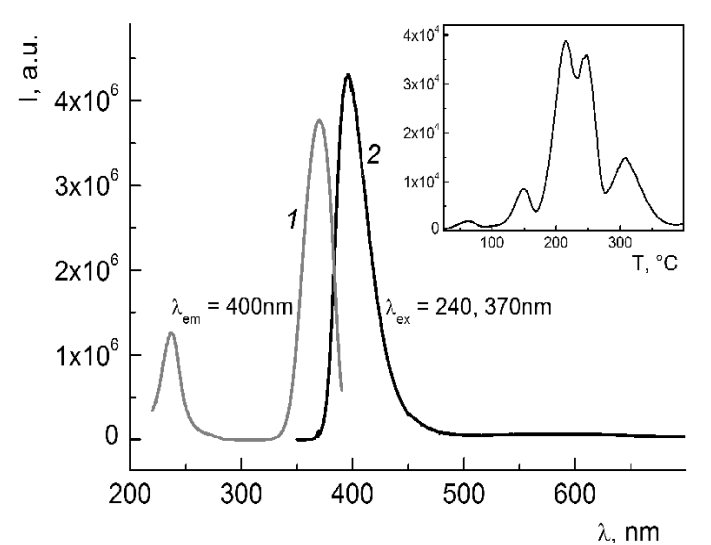

Fig. 4. Excitation (1) and photoluminescence (2) spectra of nominal pure YAG crystal grown under reduced atmosphere. Insert: thermostimulated luminescence of X-ray irradiation.

undoped YAG is high and close to that in the carbon-doped crystals. This results and the similarity of properties indicate that nominally pure YAG grown under the reducing atmosphere is considerably contaminated with carbon. The real nature of the carbon centers is not clearly understood so far. It is assumed that such centers are associated with the native structure defects $\left(\mathrm{F}^{+}\right.$center and/ or antisite $\mathrm{Y}_{\mathrm{Al}}^{3+}$ [27]) or carbon impurity [20, 21].

Strong luminescence in the near-IR range with the narrow peak at $800 \mathrm{~nm}$ was found in some crystals under the UV excitation (Fig. 5). Two absorption peaks at $\sim 210$ and $255 \mathrm{~nm}$ are typical for this case. The absorption and emission bands essentially enforced after post-grown annealing under oxygen atmosphere. Previously, the similar optical characteristics were observed for $\mathrm{Fe}$ doped YAG crystals [17]. Therefore, the red emission can be assigned to the $\left(\mathrm{O}^{2-}-\mathrm{Fe}^{3+}\right)$ charge transfer which is in a good agreement with the luminescence excitation and

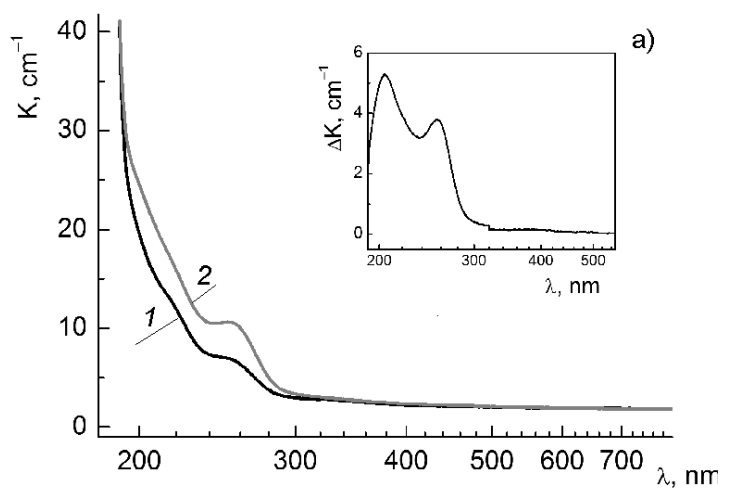

emission spectra. Recently the same strong luminescence peak at $800 \mathrm{~nm}$ was found and attributed to the low level of iron impurity in undoped YAG single crystals $[10,18]$. The photoluminescence studies have shown the influence of this impurity on the emission efficiency of Ce:YAG. This proves that not only trapping defects are responsible for the low efficiency of scintillation in Ce:YAG. Impurities also compete with $\mathrm{Ce}$ ions and reduce their green emission [24].

Study of YAG crystal X-ray excited luminescence reveals the wide band in uv range with the maximum at $290-340 \mathrm{~nm}$ and a weak shoulder near $400 \mathrm{~nm}$ (Fig. 6). As was claimed in $[13,22,23,27-30]$ UV luminescence consists of the bands attributed to self-trapped exciton (STE) and intrinsic defects. The STE emission was found near $260 \mathrm{~nm}$ at low temperature, whereas more thermally stable luminescence bands were detected in the range of $290-340 \mathrm{~nm}$ up to the room temperature. Analysis of data presented in [24] shows that a broad UV peak near $300 \mathrm{~nm}$ has been well-documented, and several papers report the intense UV emission under X- and $\gamma$ - excitation. This UV emission have been attributed to intrinsic defects lattice including impurities, oxygen vacancies, aluminum vacancies and $\mathrm{Y}_{\mathrm{Al}}{ }^{3+}$ antisites. The more recent study suggests the color centers and $\mathrm{Y}_{\mathrm{Al}}{ }^{3+}$ antisites as dominant contributors to $300 \mathrm{~nm}$ emission in YAG grown from melt. The enhancement in X-ray luminescence intensity due to suppression of shallow and deep trap was shown in [25].

Scintillation properties of the undoped YAG crystals associated with the intrinsic lattice defects were presented in $[12,26]$. It was found that undoped YAG crystal is a promising scintillator emitting in UV region

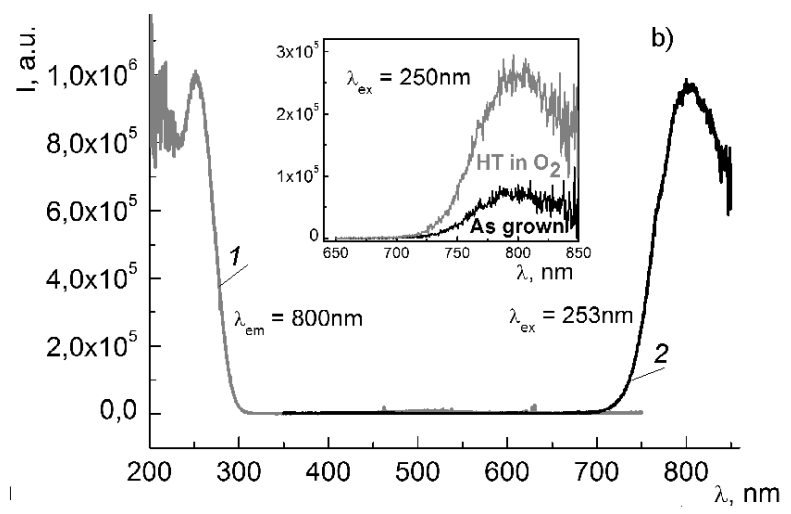

Fig.5. a) Absorption spectra of (1) as grown and (2) annealed under oxygen $\left(1200^{\circ} \mathrm{C}, 1 \mathrm{~h}\right)-\mathrm{YAG}$ crystal. Insert: induced absorption. b) Excitation (1) and photoluminescence (2) specta of as-grown crystal. Insert: oxygen annealing impact on luminescence. 
Table. Host defects in YAG crystals

\begin{tabular}{||c|c|c|c|c||}
\hline \hline Absorption, $\mathrm{nm}$ & Excitation, $\mathrm{nm}$ & Luminescence, $\mathrm{nm}$ & Supposed origin & Reference \\
\hline 182 & 174 & $260(<77 \mathrm{~K})$ & $\mathrm{STE}$ & $8,9,13,27-30$ \\
& 180 & 294 & $\mathrm{STE}(\mathrm{AD})$ & $6,8,13$ \\
& 182 & 323 & $\mathrm{STE}\left(\mathrm{Y}_{\mathrm{Al}}\right)$ & 9 \\
370 & 370 & 334 & $\mathrm{Y}_{\mathrm{Al}}(\mathrm{AD})$ & 9 \\
370 & 371 & 397 *Carbon doped & $\mathrm{F}^{+}\left(\mathrm{Y}_{\mathrm{Al}}\right)$ & 9 \\
$169,205,298$ & $169,205,298$ & $450-490<80 \mathrm{~K} n / \gamma$ & $\mathrm{F}^{+} / \mathrm{C}_{\mathrm{Al}}$ & $10,19-21$ \\
$353,495,833$ & & induced & & $27,31-33$ \\
\hline
\end{tabular}

with light yield of $14,300 \mathrm{ph} / \mathrm{MeV}$ and decay time $\sim 460 \mathrm{~ns}\left(\gamma{ }^{137} \mathrm{Cs} 662 \mathrm{keV}\right)$.

Finally the summary of the main experimental data on absorption and luminescence parameters as well as supposed origins of the defects in the undoped YAG crystals are presented in Table.

Thermochemical treatment and radiation induced color centers also affect the laser and scintillation efficiency. However, relatively few is known about the nature of the intrinsic and extrinsic defects in the crystals. These defects are always present in YAG crystals and have to be taken into account during the analysis of the activated $\left(\mathrm{Ce}^{3+}\right.$, $\mathrm{Pr}^{3+}$, etc.) crystals, because their concentrations are comparable. It means that probabilities of interaction between intrinsic defects and activator ions are very high, making this factor important for scintillation performance.

Stoichiometry deviation in the YAG crystals was studied by numerical simulation, XRD, EPR, luminescence spectroscopy and other methods [5, 6, 36-40]. The simulation results indicate that the intrinsic disorder in stoichiometric YAG is dominated by the antisites. The most stable antisite defects (AD) are represented by nearby located $Y_{A l}$ and $A l_{Y}$. In addition to the thermally induced intrinsic defects, extrinsic defects may be created through interaction with the growth atmosphere. Therefore, the defects associated with deviations from stoichiometry are not strictly intrinsic defects. Nevertheless, any deviation from stoichiometry calls a formation of compensating defect, or series of defects, that may limit the performance of scintillators stronger than the intrinsic defects. These defects form shallow electron traps, which may hinder the scintillation response by obstructing the transfer

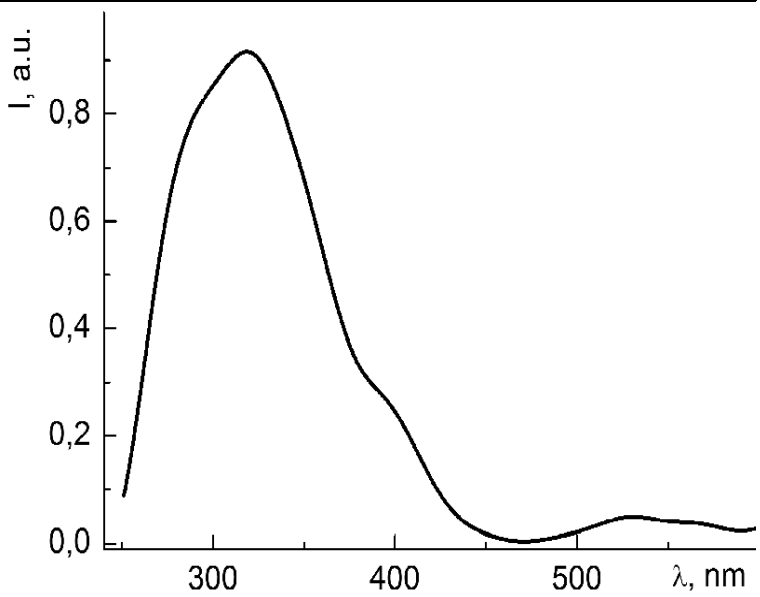

Fig. 6. X-ray luminescence spectrum of pure YAG crystals at $300 \mathrm{~K}$.

of charge carriers to the luminescent center [41].

Opinions on the role of $\mathrm{AD}$ are currently under discussion. Thus, the recent studies on defects in the YAG single crystals have shown that the dominant defects in the single crystals are $\mathrm{Al}$ vacancies, O-vacancies and $\mathrm{Al}-\mathrm{O}$ vacancies $[11,42]$. Based on positron lifetime spectroscopy measurements and defect wavelength dispersive X-ray measurements, the authors anticipate the presence of the $\mathrm{Y}_{\mathrm{Al}}{ }^{3+}$ antisite defects to the low formation energy of their formation predicted from first principle calculations $[5,6,38]$. They consider that air or oxygen annealing can significantly reduce or eliminate the color centers in the YAG single crystals [11, 42]. This is important, as formation of the color centers and short-wavelength absorption increase can greatly affect the performance of the YAG crystals in laser applications. Similarly, formation of the color centers in response to the X-ray and $\gamma$-ray irradiation reduces the efficiency of YAG based crystals as scintillators. 


\section{Conclusion}

The strong relation of YAG optical properties to the presence of lattice defects (either intrinsic or induced by incorporation of foreign atoms) and nonstoichiometry is shown. In this connection, a better knowledge of the defect structure of the garnets would be desirable to tune their properties and even predict new areas of garnet crystal applications.

\section{References}

1. S.Geller, Crystal Chemistry of the Garnets, Zeitschr. Kristallographie, Bd. 125 (1967).

2. M.Kh.Ashurov, K.Voronko, V.V.Osiko et al., Phys. Stat. Sol. (a), 2, 101 (1977).

3. C.R.Varney, M.A.Khamehchi, J.Ji, F.A.Selim, J.Appl.Phys., 116, 083505 (2014).

4. Ch.Milanese, V.Buscaglia, F.Maglia et al., Chem.Mater., 16, 1232 (2004).

5. M.M.Kuklja, R.Pandey, J.Am.Ceram.Soc., 82, 2881 (1999). ^ 6. M.M.Kuklja, J.Phys. Cond. Matter., 12, 2953 (2000).

7. Y.Fujimoto, T.Yanagida, H.Yagi et al., Opt. Mater., 36, 1926 (2014).

8. Yu.Zorenko, E.Zych, A.Voloshinovskii, Opt. Mater., 31, 1845 (2009).

9. Yu.Zorenko, T.Voznyak, V.V.Gorbenko et al., Opt. Mater., 35, 2049 (2013).

10. Y.Dong, G.Zhou, J.Xu, G.Zhao et al., J.Cryst. Growth, 286, 476 (2006).

11. C.R.Varney, F.A.Selim, Color centers in YAG, AIMS Mat.Sci., 2, 560 (2015).

12. V.I.Chani, A.Yoshikawa, Y.Kuwano et al., J. Cryst. Growth, 204, 155 (1999).

13. Yu.Zorenko, A.Voloshinovskii, V.Savchyn et al., Phys. Stat. Sol. (b), 244, 2180 (2007).

14. Shaped Crystals: Micro-pulling-down Technique and Growth, ed. by T.Fukuda, V.I.Chani, Springer, Berlin-New York (2007).

15. Handbook of Crystal Growth, 2nd Edition, ed. by P.Rudolph, Elsevier (2014).

16. P.Arhipov, S.Tkachenko, S.Vasyukov et al., Functional Materials., 21, 472 (2014).

17. M.V.Korzhik, M.G.Livshits, N.I.Zotov et al., Zh.Prikl.Spektr., 48, 637 (1988).

18. C.R.Varney, S.M.Reda, D.T.Mackay et al., AIP Advances, 1, 042170 (2011).
19. M.S.Kulkarni, K.P.Muthe, N.S.Rawat et al., Rad. Meas., 43, 492 (2008).

20. X-B.Yang, H.-J.Li, Q-Yu.Bi et al., J.Appl. Phys., 104, 123112 (2008).

21. X-B.Yang, J.Xu, H.-J.Li et al., J.Appl.Phys., 106, 033105 (2009).

22. Yu.Zorenko, A.Voloshinovskii, I.Konstankevych et al., Radiat. Meas., 38, 677 (2004).

23. Yu.Zorenko, V.Gorbenko, I.Konstankevych et al., J.Luminescence, 114, 85 (2005).

24. D.T.Haven, D.Solodovnikov, M.H.Weber et al., Appl.Phys. Lett., 101, 041101 (2012).

25. C.R.Varney, M.A.Khamehchi, Ji.Ji, F.A.Selim, Rev. Sci. Instr., 83, 103112 (2012).

26. M.Seki, V.V.Kochurikhin, S.Kurosawa et al., Phys. Stat. Sol. C, 9, 2255 (2012).

27. M.Springis, A.Pujats, J.Valbis, J.Phys. Cond. Matter., 3, 5457 (1991). @SPLIT =28. V.Babin, K.Blazek, A.Krasnikov, Phys.Stat. Sol. C, 2, 97 (2005).

29. D.T.Mackay, C.R.Varney, J.Buscher et al., J. Appl.Phys., 112, 023522 (2012).

30. E.Aleksanyan, M.Kirm, S.Vielhauer et al., $R a-$ diat. Meas., 56, 54 (2013).

31. A.Pujats, M.Springis, Rad.Eff.Def.Solids, 155, 65 (2001).

32. M.Kh.Ashurov, A.F.Rakov, R.A.Erzin, Sol. Stat. Comm. 120, 491 (2001).

33. V.Graveris, I.Kruminsh, Thermoact. Spectrosc. Defects in Ionic Crystals, Proceed., Latv., ed. by V.Zirap (1983), p.145

34. T.Masumoto, Y.Kuwano, Jpn.J.Appl.Phys., 24, 546 (1985).

35. K.Chakrabarti, J. Phys. Chem. Sol., 49, 1009 (1988).

36. K.Mori, Phys. Stat.Sol.(a), 42, 375 (1977).

37. A.B.Munoz-Garcia, Z.Barandiaran, L.Seijo, $J$. Mater. Chem., 22, 19888 (2012).

38 A.P.Patel, M.R.Levy, R.W.Grimes et al., Appl. Phys. Lett., 93, 191902 (2008).

39. B.Liu, M.Gu, X.L.Liu, S.M.Huang et al., Appl.Phys. Lett., 94, 121910 (2009).

40. M.J.Weber, The Role of Lanthanides in Optical Materials, in: Ceramic Transactions; ed. by B.G.Potter, A.J.Bruce, The American Ceramic Society, Westerville, OH, v.67 (1996), p.3.

41. D.Stanek, Nucl. Instr. Phys. Res. B, 266, 2657 (2008). @SPLIT =42. F.A.Selim, D.Winarski, C.R.Varney et al., Res. Phys., 5, 28 (2015). 